\title{
Draft Guidelines for Quality Control Testing of Sliding Seismic Isolation Systems
}

Harry W. Shenton III

Building and Fire Research Laboratory

Gaithersburg, Maryland 20899

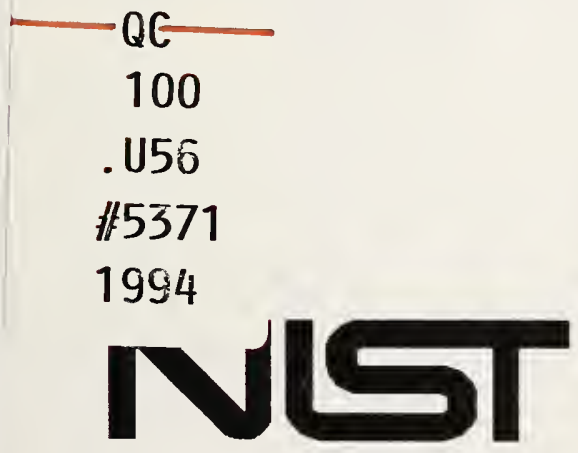

United States Department of Commerce Technology Administration

National Institute of Standards and Technology 



\section{Draft Guidelines for Quality Control Testing of Sliding Seismic Isolation Systems}

Harry W. Shenton III

\section{March, 1994}

Building and Fire Research Laboratory

National Institute of Standards and Technology

Gaithersburg, MD 20899

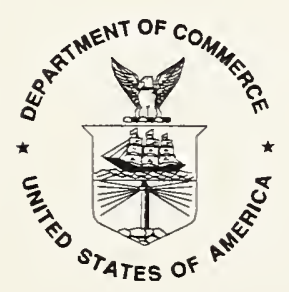

\section{U.S. Department of Commerce}

Ronald H. Brown, Secretary

Technology Administration

Mary L. Good, Under Secretary for Technology

National Institute of Standards and Technology

Arati A. Prabhakar, Director 



\begin{abstract}
Seismic isolation systems designed according to the 1991 Uniform Building Code, or the 1991 AASHTO Guide Specification for Seismic Isolation Design are required to undergo a series of prototype and quality control tests before being installed in the structure. At the present time, however, standards do not exist for conducting these tests, consequently, results are subject to unknown variability. The document represents the initiation of the process to develop standards for quality control testing of seismic isolation systems built in the U.S. The guidelines are devoted specifically to quality control testing of sliding systems (another report is devoted to quality control testing of elastomeric isolation systems). The guidelines address component part and material tests to be conducted during production, and tests on completed isolation units or components. Production tests are outlined in broad terms for a generic pure sliding device. Two completed isolation unit tests are outlined: sustained compression, and effective stiffness and energy dissipation. Complete details of the test set-up, test procedure, data acquisition, analysis and reporting of results are given in the guidelines. Performance criteria are established for all tests, systems that do not meet these criteria may not perform satisfactorily in service should be set aside for disposition by the engineer of record.
\end{abstract}





\section{Acknowledgements}

The author would like to thank the NIST Oversight Committee for their guidance and assistance in developing these guidelines. The committee includes Dr. Ian Buckle, Dr. Charles Kircher, Professor James M. Kelly, Dr. Ronald Mayes and Dr. Victor A. Zayas. Their time and effort are greatly appreciated. 



\section{TABLE OF CONTENTS}

ABSTRACT $\ldots \ldots \ldots \ldots \ldots \ldots \ldots \ldots \ldots \ldots \ldots \ldots \ldots \ldots \ldots \ldots$ ii

TABLE OF CONTENTS $\ldots \ldots \ldots \ldots \ldots \ldots \ldots \ldots \ldots \ldots \ldots$

LIST OF FIGURES $\ldots \ldots \ldots \ldots \ldots \ldots \ldots \ldots \ldots \ldots \ldots \ldots$

1. INTRODUCTION ......................... 1

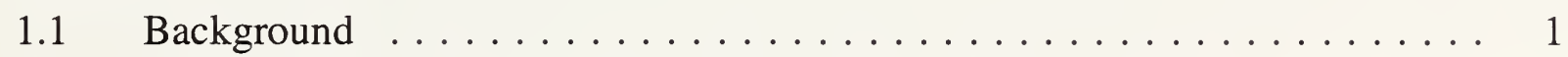

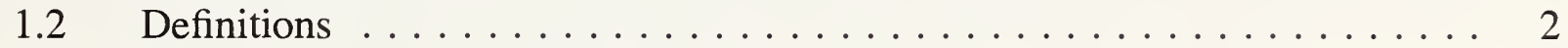

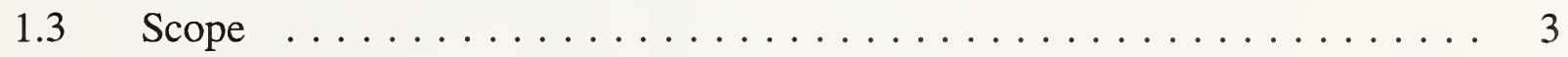

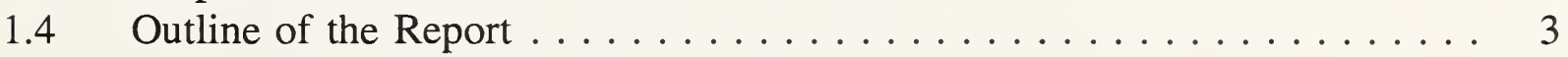

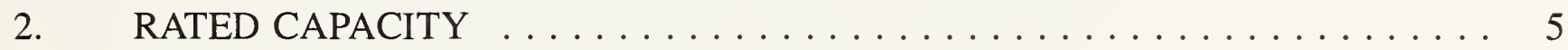

3. PRODUCTION TESTS ....................... 7

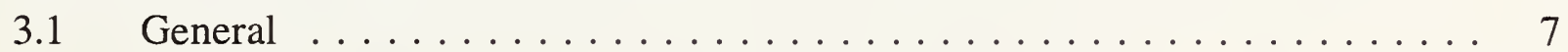

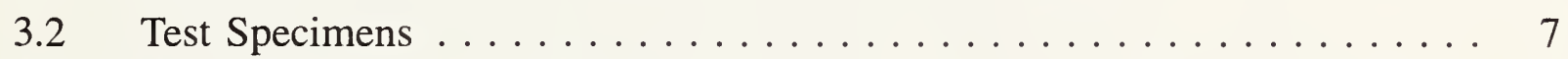

3.3 Test Schedule . . . . . . . . . . . . . . . . . . . 8

3.4 Report of Results $\ldots \ldots \ldots \ldots \ldots \ldots \ldots \ldots$

4. COMPLETED ISOLATION UNIT TESTS . . . . . . . . . . . . . 11

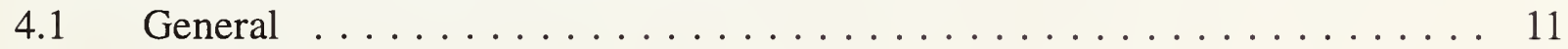

4.2 Sustained Compression $\ldots \ldots \ldots \ldots \ldots \ldots \ldots \ldots \ldots \ldots \ldots$

4.3 Effective Stiffness and Energy Dissipation $\ldots \ldots \ldots \ldots \ldots \ldots$

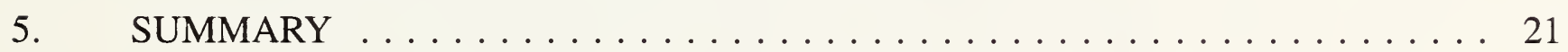

REFERENCES .............................. 23

APPENDIX A. SYMBOLS AND NOTATION . . . . . . . . . . . . . . . 25

APPENDIX B. GLOSSARY OF TERMS . . . . . . . . . . . . . . . . . . 27 



\section{LIST OF FIGURES}

Figure 3.1. Schematic of a Generic Plane Sliding Device . . . . . . . . . . . . . 8

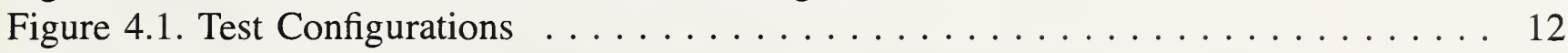

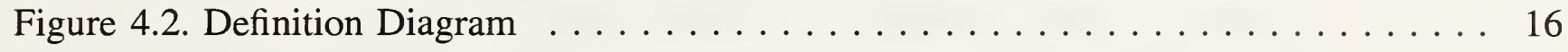





\section{INTRODUCTION}

\subsection{Background}

Seismic isolation is gradually being accepted by building owners, architects and structural engineers as a viable alternative for design and retrofit of certain classes of structures. This is due in part to the two building codes which recently adopted provisions for the design and construction of seismically isolated structures: for buildings, the Uniform Building Code (UBC) (Uniform, 1991) and for bridges, the American Association of State Highway and Transportation Officials (AASHTO), Guide Specifications for Seismic Isolation Design (Guide, 1991). The number of projects to consider seismic isolation has increased noticeably since the release of these documents.

The UBC and AASHTO Guide each rely heavily on testing of the isolation system for design and construction of isolated structures. Two class of tests are currently required by the codes: prototype tests and quality control (QC) tests. These may be loosely defined as follows:

Prototype tests are project specific and are conducted to verify the design properties of the isolation system prior to construction.

Quality Control tests are project specific and are conducted to verify the quality of manufacture and as-built properties of the isolation system prior to installation. This generally includes tests conducted during fabrication (production tests), on materials or component parts of the isolation system, and tests on completed units.

A third class of tests, referred to here as Pre-Qualification tests, are defined herein as follows:

Pre-Qualification tests need not be project specific and are conducted in order to establish the fundamental properties and characteristics of the isolation system, and to determine the extent to which these properties and characteristics are dependent on load and environmental factors.

Formal pre-qualification tests as defined above are not required by the codes at the present time, but are usually conducted in some form or another as a new system is developed.

At the present time standards do not exist for conducting any of these tests. Skeleton guidelines for prototype testing are provided in the UBC and AASHTO Guide, but these amount to a simple description of the load sequence and essential parameters needed to conduct the test. The AASHTO Guide addresses quality control testing in a cursory manner. Consequently, tests conducted today, as required by the codes, are subject to unknown variability.

This document represents the initiation of the process to develop standards for quality control testing of seismic isolation systems (therefore the title "Draft Guideline..." ). This report is devoted specifically to QC testing of sliding seismic isolation systems (defined shortly). A similar report is devoted to QC testing of elastomeric seismic isolation systems. Guidelines for prequalification and prototype testing are the subject of a third report. 
The final "Guidelines..." will be published after thorough review and evaluation of the draft guidelines. The review and evaluation process is to involve broad industry input and a testing component. The completed "Guidelines.." will then be submitted to code writing organizations and regulatory agencies in consideration for adoption.

\subsection{Definitions}

The following definitions are intended to assist the reader in interpretation of the Guidelines:

An Isolation System is defined as the collection of Isolation Units, Isolation Components and all other structural elements that transfer force between the foundation/substructure and the superstructure. The Isolation System as a package provides the lateral flexibility and damping necessary for effective isolation, and high initial stiffness required to resist wind load. Some Systems also include an ultimate restraint or "fail-safe" mechanism, that is meant to engage at very large displacements or provide back-up support in case of failure of the isolation system.

An Isolation Unit is defined as a device that provides all the necessary characteristics of the System in an integral device.

An Isolation Component is defined as a device that provides some of the necessary characteristics of the System (e.g., flexibility or damping) in a single device.

A number of different seismic isolation systems are currently in use or under development today. The systems can, however, generally be classified as primarily elastomeric, primarily sliding or hybrid. These are briefly defined as follows:

Elastomeric systems use alternating layers of steel and elastomer, bonded together to form an integral bearing that is free of joints. The laminated bearing provides the vertical stiffness, lateral flexibility and damping characteristics necessary for seismic isolation. Variations on the basic design use lead cores to provide damping in the system.

Sliding systems use two dissimilar materials to form an interface that permits relative movement between the two surfaces. Friction acts between the materials and serves to dissipate energy upon sliding. Depending on the design, an auxiliary mechanism or component is sometimes needed to provide a restoring/recentering force.

Hybrid systems generally use independent components to provide the restoring force, damping, wind restraint and ultimate restraint. Components can be integrated or in close proximity to each other, or distributed throughout the 
isolation interface. Hybrid systems sometimes include aspects of one or both of the other class of systems.

A table of Symbols and Notation is contained in Appendix A. Other definitions and terms are presented in Appendix B.

\subsection{Scope}

The Guidelines for pre-qualification and prototype testing can, and should be independent of the type of isolation system. However, at least in part, quality control tests tend to be system specific, simply because production tests are unique to the design, materials and construction of the device. Therefore, this report is limited in scope to QC tests for sliding isolation systems. The Guidelines may be applicable to certain components of a hybrid system: the Guidelines should be thoroughly reviewed by the engineer to determine the applicability of particular tests.

The Guidelines are intended for systems that isolate in the horizontal plane only, i.e., the system is assumed to be essentially rigid in the vertical direction. Guidelines for testing of vertical isolation systems are not included. In addition, the Guidelines are intended for passive isolation systems only. Although it is likely that some of the tests are applicable to components of active or semi-active systems, the Guidelines were not written with these systems in mind.

The Guidelines are not intended to serve as a specification or manufacturing standard for sliding isolation units, nor are they intended to serve as a comprehensive quality control program. Rather, the guidelines outline the minimum recommended Production and Completed Unit tests that should be completed as part of the quality control program.

Note, the capacity of all Isolation Units and Components must be "rated" prior to testing. The onus of responsibility is on supplier of the isolation system to report the properties and characteristics of the system. This includes specifying the range of operating loads and environmental conditions under which the system can be expected to function as designed. The concept of rated capacity is fundamental to the guidelines: the load, displacement, frequency, etc., of the test procedures are based on the rated capacity of the system. The concept of rated capacity carries through from pre-qualification, to prototype, to QC testing. A standard list of properties to be rated has been developed to cover all tests.

\subsection{Outline of the Report}

Presented in Chapter 2 is the list of properties and characteristics of the Unit or Component to be rated prior to testing. Presented in Chapter 3 are guidelines for production tests. These tests are conducted on the materials and component parts that go into making a sliding Isolation Unit or Component. Presented in Chapter 4 are Guidelines for completed unit tests. A summary is presented in Chapter 5. 
Although the entire document is considered "draft", certain issues and details remained to be resolved at the time of writing. In some cases these are details that pertain to a specific test, and in other cases it concerns the decision to include or exclude a particular test in its entirety. Where possible, different options, or the range of parameters that have been considered or are proposed for a particular test are presented. Draft options are preceded or enclosed in a shaded box like the one shown below:

Draft Option 


\section{RATED CAPACITY}

The nominal capacity of all Isolation Units and Components must be "rated" by the supplier prior to testing. Properties or characteristics to be rated are listed below, along with the parameter notation and a short description.

\section{Parameter}

Stiffness:

Horizontal

Horizontal under Wind

Vertical

Energy Dissipation

Lateral Deformation:

Design Displacement

Maximum Displacement
$K_{H} \quad$ Effective horizontal stiffness at the Design Displacement and Design Vertical Load.

$K_{W} \quad$ Effective horizontal stiffness at the Design Wind Load and Design Vertical Load.

$K_{V} \quad$ Effective vertical stiffness at the Design Vertical Load.

$E_{H} \quad$ Energy dissipated per cycle at the Design Displacement and Design Vertical Load.

D Nominal displacement capacity, including that resulting from torsion,

\section{Draft Option}

corresponding to a level of ground motion that has a 10 percent probability of being exceeded in a 50 year period.
Thermal Displacement

Vertical Deformation:

Design Displacement

Creep Displacement
$D_{T M}$

Total maximum displacement capacity, including that resulting from torsion,

\section{Draft Option}

corresponding to a level of ground motion that has a 10 percent probability of being exceeded in a 100 year period.

$D_{t} \quad$ Nominal thermal displacement capacity.

$D_{V} \quad$ Nominal vertical displacement under the Design Vertical Load.

$D_{c} \quad$ Creep displacement under the Design Vertical Load. 
Rotation

Compression:

Low

Design Vertical Load

High

Tension

Lateral Load:

Wind

Braking/Centrifugal load

Degradation Cycle Limit

Thermal Cycle Limit

\section{Notation Description}

$\theta$

Nominal rotation capacity about an axis in the horizontal plane, and perpendicular to the direction of lateral loading under the Design Vertical load.

$P_{L} \quad$ Lower limit of load range of satisfactory seismic performance, includes the effect of vertical ground motion and overturning.

$P_{D} \quad$ Nominal capacity in compression for dead and live load.

$P_{U} \quad$ Upper limit of load range of satisfactory seismic performance, includes the effect of vertical ground motion and overturning.

$P_{T} \quad$ Nominal capacity in tension.

$F_{W} \quad$ Nominal wind load capacity.

$F_{b} \quad$ Nominal braking/centrifugal load capacity.

$N_{D} \quad$ Number of cycles to $\pm D$ with a vertical load of $P_{D}$ corresponding to a $\pm 15 \%$ change in Effective Stiffness, or a $\pm 30 \%$ change in Energy Dissipation relative to the first complete cycle Effective Stiffness or Energy Dissipation, respectively.

$N_{t} \quad$ Number of cycles to $\pm D_{t}$ with a vertical load of $P_{D}$ corresponding to a $\pm 15 \%$ change in Effective Stiffness, or a $\pm 30 \%$ change in Energy Dissipation relative to the first complete cycle Effective Stiffness or Energy Dissipation, respectively.

Temperature:

Low

$T_{L} \quad$ Lower limit of operating temperature.

Design

$T_{D} \quad$ Nominal design temperature.

High
$T_{U} \quad$ Upper limit of operating temperature. 


\section{PRODUCTION TESTS}

\subsection{General}

This chapter outlines the requirements for production testing of the materials and parts of sliding Isolation Units and Components. The chapter has been developed with the intent of providing general instruction for production testing of a typical, generic sliding device. Because of the diversity of design, materials and construction of sliding devices it would be infeasible at this time to develop a specific test program that would be applicable to all sliding systems.

For the purpose of discussion the elements of a typical flat plate sliding device are illustrated in Figure 3.1 and defined in the following. The device consists of two plate assemblies, one that is fixed and one that is free to slide relative to the fixed plate. The fixed assembly consists of a backing plate, and an interface material that will be referred to here as the "bearing pad". The bearing pad is usually recessed into the backing plate and is bolted, bonded, or bolted and bonded to the plate. The sliding assembly consists of a backing plate, and a highly polished interface material that will be referred to here as the "sliding surface". For a typical Teflon-stainless steel sliding device the bearing pad is made of Teflon (e.g., unfilled, filled or woven) and the sliding surface is a polished stainless steel. Although it can be placed on the bottom (i.e., reverse of that shown in Figure 3.1), the sliding surface is normally placed on top to keep dirt and particles from contaminating the surface.

There are numerous variations on the generic sliding device, some of which use multiple sliding interfaces (Mostaghel, 1988) and others that use cylindrical or spherical sliding interfaces (e.g., Zayas et al, 1990). The tests described are recommended for all designs that consist of a bearing pad and sliding surface. The tests are considered the minimum required, others may be specified by the engineer as needed.

For each test a performance criterion is established that is based on a design specified value. These performance criteria are considered to be minimum requirements. Materials and parts that do not meed or exceed these requirements should be rejected and should not be used in the fabrication of Units or Components.

\subsection{Test Specimens}

Unless otherwise specified the results should be reported as the average of the results from 3 independent test specimens or 3 independent readings, unless more are specifically required by a referenced standard or procedure. In any case, individual test results should be reported along with the average value. Material properties shall be determined from specimens cut from the stock used in the fabrication of the device, or from test pieces molded from the same stock or bulk material. Tests may be conducted on specimens taken from actual devices, at the request of the engineer. 


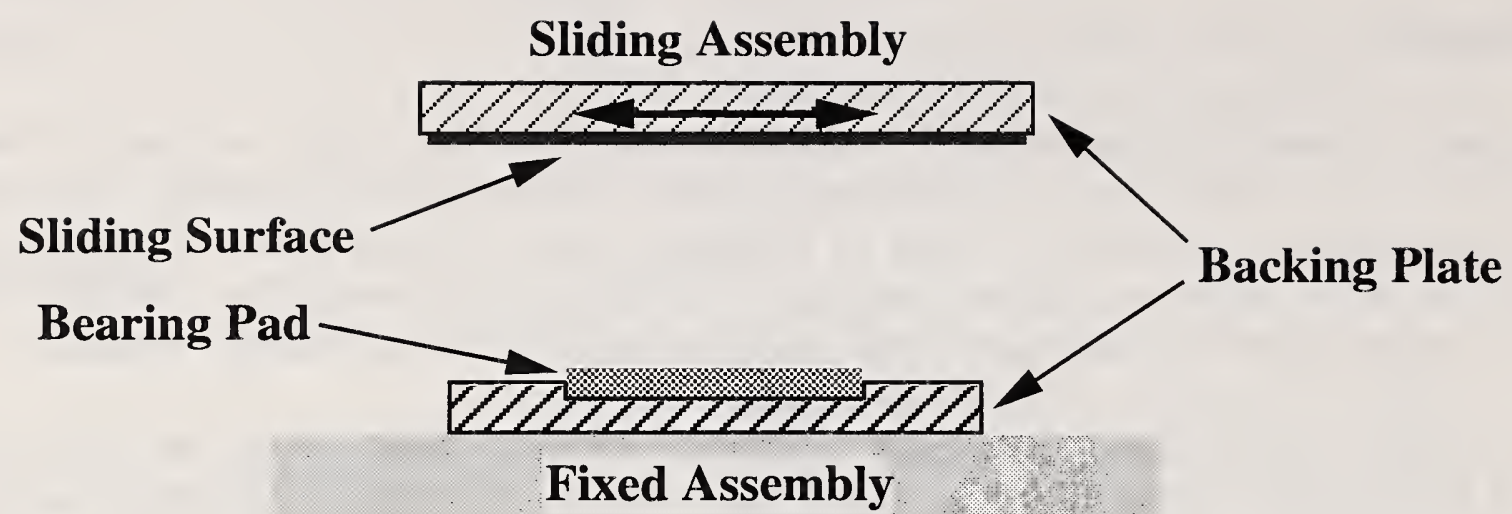

Figure 3.1. Schematic of a Generic Plane Sliding Device

\subsection{Test Schedule}

3.3.1 Surface Roughness - The finish of the sliding surface shall be established by visual comparison to three calibrated roughness specimens. The surface finish of the three calibrated roughness specimens shall correspond to the maximum, mean and minimum surface roughness as specified for production of the Isolation Units. The surface roughness of the sliding surface shall be within the range of the specified minimum to maximum surface roughness. The finish of the three calibrated roughness specimens shall be determined and expressed in terms of Roughness Average, $R_{a}$, as defined in ANSJ/ASME B46.1-1985 Appendix C. The Roughness Average shall be determined along 3 non-colinear lines, oriented at angles of 0,45 and 90 degrees from the 0 degree direction. Ten readings evenly spaced along each line shall be taken. The Roughness Average reported shall be the average of the 30 readings.

3.3.2 Trueness of Surface - In order to ensure full contact of the bearing pad and sliding surface for the range of motion anticipated, the surfaces are to be true to within the design specified value. The deviation from flatness of a plane surface shall be established by direct measurement of the surface and shall be within the design specified tolerance. The deviation from a theoretical circular or spherical surface shall be established by direct measurement and shall be within the design specified tolerance.

3.3.3 Interface Material Properties - Interface materials (bearing pad and sliding surface) shall have the mechanical, physical, frictional, wear and weathering properties as specified by the design. Where applicable, materials may be specified by an accepted standard and shall have properties to within the specified tolerance as outlined by the standard, and determined using accepted test procedures. New or unique materials that are not specified by an accepted standard shall be tested using accepted procedures and shown to be in compliance with the specification. Typical properties to be evaluated might include tensile strength, elongation to break, creep, corrosion and wear characteristics, and low and high temperature properties. Some of these may not be applicable or other property tests may be specified by the engineer as needed. 
3.3.4 Backing Material Properties - Backing plate materials shall have the mechanical, physical, and weathering properties as specified by the design. Materials may be specified by an accepted standard, where applicable, and shall have properties to within the specified tolerance as outlined by the standard and determined using accepted test procedures. New or unique materials that are not specified by an accepted standard shall be tested using accepted procedures and shown to be in compliance with the design specification.

3.3.5 Bearing Pad Attachment - The primary means of attachment (bonding or mechanical) of the bearing pad to the backing plate shall be established by a submitted and accepted quality control procedure. The quality control procedure used for production units shall be the same as that used in the prototype units.

3.3.6 Sliding Interface Attachment - The primary means of attachment (bonding or mechanical) of the sliding interface to the backing plate shall be established by a submitted and accepted quality control procedure. The quality control procedure used for production units shall be the same as that used in the prototype units.

\subsection{Report of Results}

Results of the tests shall be documented in a clear and concise report. Unless otherwise specified the report should include but is not limited to the following. The name or type of test, the laboratory or institution conducting the test, name of the technician or engineer responsible for the test, date and time of the test. Pertinent test parameters shall be indicated in the report and results clearly stated. For test results that are based on the average of several individual test results or measurements, the individual results shall be reported in addition to the overall average. The report shall indicate whether the specimen passed or failed the test based on the stated performance criteria. For specimens that fail the test, the report shall explain in sufficient detail the reason for failure. 



\section{COMPLETED ISOLATION UNIT TESTS}

\subsection{General}

This chapter outlines the requirements for quality control testing of completed Isolation Units and Components. Two tests are outlined by the Guidelines: Sustained Compression, and Effective Stiffness and Energy Dissipation. The completed Unit/Component tests are designed to ensure quality of the manufactured product and to establish conformity, within a specified tolerance, with the specified design properties. These tests are a recommended minimum, others may be specified by the engineer as needed.

Detailed requirements are outlined for each test. This includes test specimens, requirements of the test facility, instrumentation and calibration, data acquisition, test procedure, data analysis and reporting of results. Performance criteria are defined for each test and are to be evaluated based on the test results. Units or Components that do not meet or exceed these requirements shall be set aside for disposition by the engineer of record.

The Guideline recommendation is that most, if not all, Isolation Unit/Component manufactured be tested as part of the quality control program: a moderately large number of rejected Units/Components (e.g., 15-20\% of a lot, or more) may indicate a fundamental flaw in the manufacturing process. Is it recommended that should more than $15 \%$ of the Units/Components of a particular lot be rejected, the engineer evaluate the available data and consider rejection or acceptance of the entire lot.

Note - for the remainder of this Chapter the term "Unit" refers to both sliding Isolation Units and sliding Isolation Components.

\subsection{Sustained Compression}

4.2.1 Specimens - For Units that are susceptible to creep, all such Units manufactured shall be subject to the sustained compression test.

4.2.2 Test Facility - Tests shall be conducted in a facility that is capable of applying a static vertical load, continuously for up to 12 hours without interruption. Tests may be conducted in a single or dual specimen configuration, as illustrated in Figure 4.1. The vertical load capacity of the facility shall be at least 1.6 times the nominal load capacity $\left(P_{D}\right)$ of the Isolation Unit(s) to be tested. The vertical load may be applied under load control or displacement control. The facility shall be capable of maintaining an average vertical load within $\pm 10 \%$ of that specified at all times, for the duration of the test.

The vertical load system shall be verified in accordance with ASTM E4 to an accuracy of $\pm 5 \%$. Load verification shall be carried out with the actual equipment to be used in the test. The test facility shall be verified annually, or, after repair, replacement or relocation of test facility equipment. 


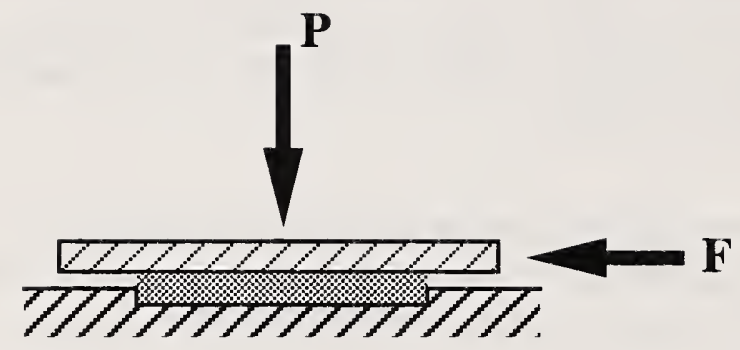

(a.) Single

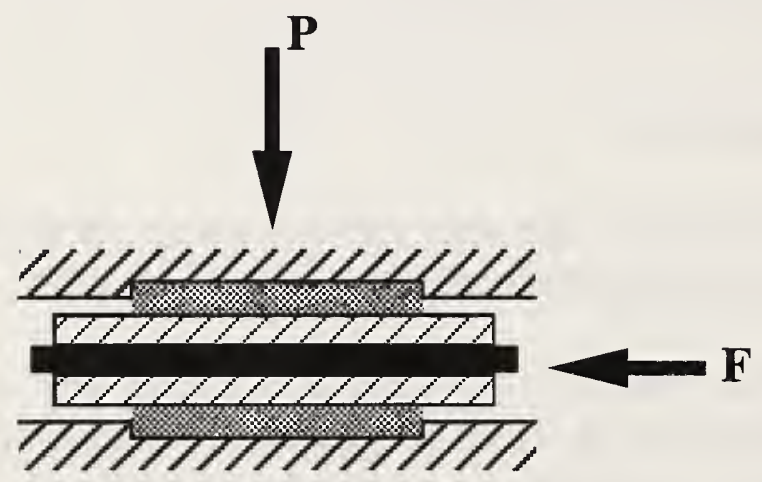

(b.) Dual

Figure 4.1. Test Configurations 


\subsubsection{Instrumentation and Calibration - None.}

4.2.4 Data Acquisition - An analog or digital data acquisition system shall be used to record vertical load for the duration of the test. Vertical load shall be recorded at least once every 30 minutes. A continuous-paper-feed strip chart recorder is suitable for recording vertical load.

4.2.5 Test Procedure - Apply a compressive load to the specimen equal to $1.5 P_{D}$. The total load shall be applied within a period of not more than 10 minutes. The total load shall be maintained for 12 hours, and within $\pm 10 \%$ of that specified for the duration of the test.

Exception - The duration of the test may be reduced to 3 hours, provided the supplier has documented evidence that there have been no failures, between 3 and 12 hours, in consecutive tests of at least 1000 production Units of a similar design, material and construction.

4.2.6 Data Analysis - From the recorded vertical load time history determine the average, maximum and minimum vertical load, from the time the total load is reached and stabilized to the end of the test.

4.2.7 Performance Criteria - The Isolation Unit shall be visually inspected for faults a minimum of 2 times during the test, within the first 30 minutes of testing and during the last 30 minutes of testing. The Isolation Unit shall be set aside for disposition by the engineer of record if:

- it fails to sustain the applied load for any reason for the duration of the test,

- there is evidence of deformation, extrusion, cracking or debonding of the interface or backing materials,

- there is evidence of excessive creep, beyond that permitted by the design.

Where possible the Unit shall be disassembled to allow for inspection of the sliding interface.

4.2.8 Report of Results - Results of the tests shall be documented in a clear and concise report. Unless otherwise specified the report should include but is not limited to the following. The name of the laboratory or institution conducting the test, name of the technician and engineer present for the test, name of the technician or engineer responsible for the test, date and time at the start of the test, test configuration (single or dual) and specimen designation. Pertinent test parameters shall be indicated in the report, including vertical load $P_{D}$, recorded average, maximum and minimum vertical loads. The report shall indicate whether the Isolation Unit passed or failed the compression test based on the stated performance criteria. For Units that fail the test, the report shall explain in sufficient detail the reason for disposition of the Unit. 


\subsection{Effective Stiffness and Energy Dissipation}

\subsubsection{Specimens -}

\section{Draft Option}

1. All Isolation Units manufactured shall be subject to the Effective Stiffness and Energy Dissipation test.

2. If the Effective Stiffness of any Isolation Unit measured during prototype testing varies by more than $15 \%$ from the rated Effective Stiffness $\left(K_{H}\right)$, or the Energy Dissipation of any Isolation Unit measured during prototype testing varies by more than $30 \%$ from the rated Energy Dissipation $\left(E_{D}\right)$, then all Isolation Units manufactured shall be subject to the Effective Stiffness and Energy Dissipation tests as specified below.

3. A minimum of $20 \%$ of all Isolation Units manufactured in any lot shall be subject to the Effective Stiffness and Energy Dissipation test specified below. If the Effective Stiffness of any Isolation Unit measured in these tests varies by more than $15 \%$ from the rated Effective Stiffness $\left(K_{H}\right)$, or the Energy Dissipation of any Isolation Unit measured in these tests varies by more than $30 \%$ from the rated Energy Dissipation $\left(E_{D}\right)$, then all Isolation Units manufactured shall be subject to the Effective Stiffness and Energy Dissipation tests as specified below.

For Systems that consist of some combination of Units and Components, at least one set of tests shall be conducted on the combined System. The assembly and connection of the tested components shall be representative of the full System detail.

4.3.2 Test Facility - Tests shall be conducted in a facility that is capable of applying simultaneously a static vertical load and a cyclic lateral load to a specimen or group of specimens. Tests may be conducted in a single or dual specimen configuration, as illustrated in Figure 4.1. The vertical load capacity of the facility shall be at least 1.1 times the nominal load capacity $\left(P_{D}\right)$ of the Isolation Unit(s) to be tested. The test facility shall have a lateral load capacity that is at least 1.1 times the largest lateral load to be applied during the test, and a total stroke of at least twice the maximum displacement specified for the test.

The cyclic lateral load shall be applied under displacement control such that the motion of the actuator is representative of a sinusoidal wave with specified frequency. The lateral load may be applied with constant velocity such that the motion of the actuator is representative of a sawtooth wave with specified frequency, at load rates less than or equal to $250 \mathrm{~mm} / \mathrm{min}(10 \mathrm{in} / \mathrm{min})$. The vertical load may be applied under load control or displacement control. The facility shall be capable of maintaining an average vertical load within $\pm 10 \%$ of that specified at all times, for the duration of the test. The facility shall be such that the lateral load plane will remain parallel to within $\pm 5^{\circ}$ of the bottom and/or top reaction support at all times, for the duration of the test.

The vertical load system shall be verified in accordance with ASTM E4 to an accuracy of $\pm 5 \%$. The lateral load system shall be verified in accordance with ASTM E4 to an accuracy of $\pm 2.5 \%$, 
or, calibrated as described in ASTM E74 and shall have an uncertainty of not more than $\pm 2.5 \%$ of force. Load verification or calibration shall be carried out with the actual equipment to be used in the test. The test facility shall be verified or calibrated annually, or, after repair, replacement or relocation of test facility equipment.

4.3.3 Instrumentation and Calibration - Transducers shall be in place to measure, at a minimum, vertical load, lateral load and lateral displacement.

Vertical and lateral loads on the test specimen may be measured via the load read-out of the test machine, load cells in the force train or via a force transducer between the specimen and reaction support. Transducers shall be such that loads are resolved to within $1 \%$ of the specified full load. Vertical or lateral loads measured via load cells in the force train of the actuator shall be verified or calibrated as described in Section 4.3.2. Other force transducers shall be calibrated periodically as described in ASTM E74 and shall have an uncertainty of not more than $\pm 2.5 \%$ of force.

Lateral displacement shall be measured at 2 points on the lateral load plane, at opposite sides of the specimen $\left(\Delta_{1}\right.$ and $\Delta_{2}$, in Figure 4.2). Transducers shall be of sufficient precision to resolve the displacement to within $1 \%$ of the specified full displacement. Displacement transducers shall be calibrated periodically and shall have an uncertainty of not more than $\pm 2.5 \%$ of displacement. Suitable displacement transducers include but are not limited to Linear Variable Differential Transformer (LVDT), Direct Current Differential Transformer (DCDT) and Linear Resistance Potentiometer.

4.3.4 Data Acquisition- An analog or digital data acquisition system shall be used to record time, vertical load, lateral load and two lateral displacements for the duration of the test. Data shall be digitized or sampled at a rate not less than 100 times the frequency of loading. A digital data acquisition system shall be capable of sampling all data channels nearly simultaneously: the maximum time skew between channels shall be less than $1 \%$ of the sampling time interval. 

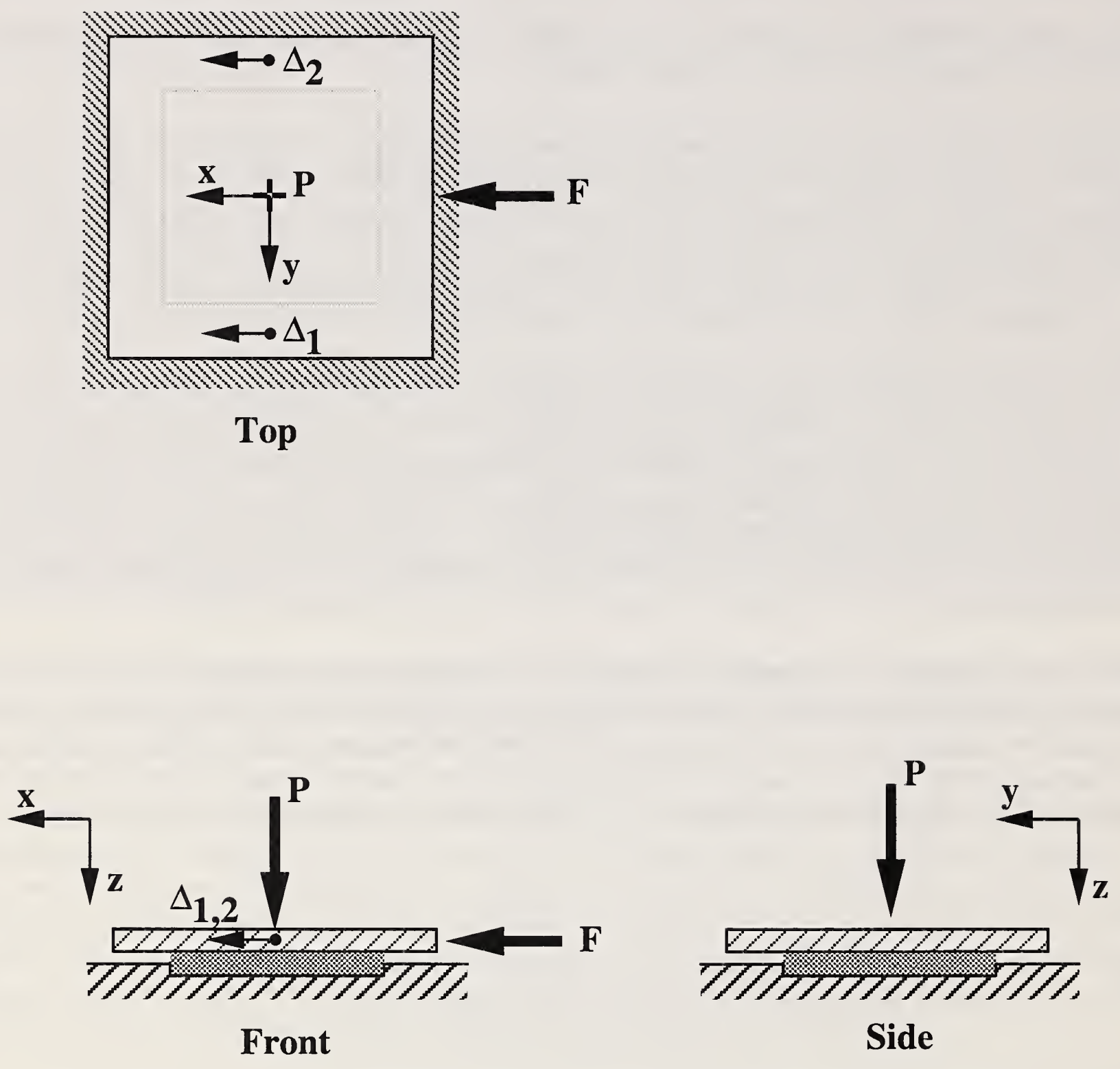

Side

Figure 4.2. Definition Diagram 
4.3.5 Test Procedure - Condition the Isolation Unit for a minimum of 24 hours at the design temperature $\left(T_{D} \pm 6^{\circ} \mathrm{C}\left(10^{\circ} \mathrm{F}\right)\right)$. Place the Isolation Unit(s) in the test machine and secure as needed to the loading plates. Apply a compressive load to the specimen equal to $P_{D}$ and allow the load to stabilize. The total load shall be applied within a period of not more than 2 minutes.

\section{Draft Option}

1. Apply a cyclic lateral load to the specimen for (option: 3 or 5 ) fully reversed cycles, to peak displacements of $\pm D$. The frequency of lateral loading shall be not less than $f_{L}$ (the lower threshold frequency ${ }^{1}$ ) or $0.004 \mathrm{cyc} / \mathrm{sec}$.

2. Apply a cyclic lateral load to the specimen for (option: 3 or 5 ) fully reversed cycles, to peak displacements of $\pm D$. The frequency of loading shall be not less than $0.004 \mathrm{cyc} / \mathrm{sec}$.

Note - the remainder of this section has been written assuming 5 fully reversed cycles. Applicable changes should be made for a 3 cycle test.

The test shall be run continuously without pause between cycles. The compressive load shall be maintained such that the average load is within $\pm 10 \%$ of $P_{D}$ and the maximum and minimum loads are within $\pm 20 \%$ of $P_{D}$ for the duration of the test.

4.3.6 Data Analysis - The time history of lateral displacement $(\Delta)$ shall be computed as the average of the measured lateral displacements $\left(\Delta_{1}, \Delta_{2}\right)$, i.e.,

$$
\Delta(t)=\frac{1}{2}\left(\Delta_{1}(t)+\Delta_{2}(t)\right)
$$

Hysteresis loops for lateral deformation shall be constructed by plotting the measured lateral load (F) versus the lateral displacement $(\Delta)$ for the 5 complete cycles of the test.

4.3.6.1 Effective Stiffness and Energy Dissipation - The Average Effective Stiffness and Average Energy Dissipation shall be computed for all Isolation Units as described in the following.

The maximum and minimum lateral displacements, $\Delta^{+}$and $\Delta^{-}$respectively, shall be established for each complete cycle. The maximum and minimum lateral loads, $F^{+}$and $F^{-}$respectively, shall be established for each complete cycle. Effective Stiffness $\left(K_{H_{i}}\right)$ for each cycle $i$ shall be computed as follows,

${ }^{1}$ The lower threshold frequency $f_{L}$ is evaluated as described in "Draft Guidelines for PreQualification and Prototype Testing of Seismic Isolation Systems," (Shenton, 1993). Tests conducted at rates less than $f_{L}$ do not yield results that are representative of the behavior expected during an actual seismic event. 


$$
K_{H_{i}}=\frac{F^{+}-F^{-}}{\Delta^{+}-\Delta^{-}}
$$

Note - for systems that exhibit an elastic-perfectly plastic hysteretic behavior (e.g., a pure sliding device with no restoring force capability) the maximum and minimum forces shall be those corresponding to the maximum and minimum displacements, $\Delta^{+}$and $\Delta^{\prime}$, respectively.

The Average Effective Stiffness $\left(K_{H}\right)$ shall be computed for the 5 complete cycles of the test, as given by

$$
K_{H}=\frac{1}{5} \sum_{1}^{5} K_{H_{i}}
$$

Energy Dissipation shall be determined for each complete cycle of the test. The energy dissipated in cycle $i\left(E_{H_{i}}\right)$, is equal to the area enclosed by the hysteresis loop for that cycle and should be expressed in units of force-length (e.g., $\mathrm{kN}-\mathrm{mm}$, or kip-in, etc.). The area enclosed by the loop may be determined by numerical integration for digital data, or by other suitable means for analog data. The Average Energy Dissipation $\left(E_{H}\right)$ shall be determined for the 5 complete cycles of the test, as given by

$$
E_{H}=\frac{1}{5} \sum_{1}^{5} E_{H_{i}}
$$

4.3.6.2 Static and Kinetic Coefficients of Friction - The Static Coefficient of Friction and the Average Kinetic Coefficient of Friction shall be determined as described in the following, for Isolation Units that exhibit an elastic-perfectly plastic hysteretic behavior.

The "break-away" force $\left(F_{s}\right)$, defined as the minimum force required to initiate relative movement across the sliding interface, shall be established from the first quarter cycle of the recorded loaddeflection data. The Static Coefficient of Friction shall be computed as the ratio of the breakaway force to vertical load, i.e.,

$$
\mu_{s}=\left|\frac{F_{s}}{P_{s}}\right|
$$

where $P_{s}$ is the measured vertical load corresponding to $F_{s}$.

The average lateral load $\left(F_{A V E}\right)$ and the average vertical load $\left(P_{A V E}\right)$ shall be determined for each of the nine complete half cycles of loading, in the range of displacements $-0.95 \mathrm{D}$ to $0.95 \mathrm{D}$. The Kinetic Coefficient of Friction shall be computed for half cycle $i$ as the ratio of average lateral load to average vertical load, i.e.,

$$
\mu_{k_{i}}=\left|\frac{F_{A V E}}{P_{A V E}}\right|
$$


The Average Kinetic Coefficient of Friction $\left(\mu_{\mathrm{k}}\right)$ shall be computed for the nine complete half cycles of loading, as given by

$$
\mu_{k}=\frac{1}{9} \sum_{1}^{9} \mu_{k_{i}}
$$

4.3.7 Performance Criteria - The Isolation Unit shall be set aside for disposition by the engineer of record if the Average Effective Stiffness is not within $\pm 15 \%$ of the average of the Average Effective Stiffnesses of all Units of a similar design and capacity, i.e., the Unit must satisfy the following:

$$
\frac{\left|K_{H}-K_{H_{A V E}}\right|}{K_{H_{A V E}}} \leq 0.15
$$

in which $K_{H}$ is the Average Effective Stiffness of a particular Unit and $K_{H_{\text {VVI }}}$ is the average of the Average Effective Stiffnesses of all Units of a similar design and capacity.

The Isolation Unit shall be set aside for disposition by the engineer of record if the Average Energy Dissipation is not within $\pm 15 \%$ of the average of the Average Energy Dissipation of all Units of a similar design and capacity, i.e., the Unit must satisfy the following:

$$
\frac{\left|E_{H}-E_{H_{A V E}}\right|}{E_{H_{A V E}}} \leq 0.15
$$

in which $E_{H}$ is the Average Energy Dissipation of a particular Unit and $E_{H_{A v E}}$ is the average of the Average Energy Dissipation of all Units of a similar design and capacity.

For systems that exhibit an elastic-perfectly plastic hysteretic behavior, the Isolation Unit shall be set aside for disposition by the engineer of record if the Static Coefficient of Friction is not within $\pm 15 \%$ of the average of the Static Coefficients of Friction of all Units of a similar design and capacity, i.e., the Unit must satisfy the following:

$$
\frac{\left|\mu_{s}-\mu_{s_{A V E}}\right|}{\mu_{s_{\text {AVE }}}} \leq 0.15
$$

in which $\mu_{\mathrm{s}}$ is the Static Coefficient of Friction of a particular Unit and $\mu_{s_{A V E}}$ is the average of the Static Coefficients of Friction of all Units of a similar design and capacity.

For systems that exhibit an elastic-perfectly plastic hysteretic behavior, the Isolation Unit shall be set aside for disposition by the engineer of record if the Average Kinetic Coefficient of Friction is not within $\pm 15 \%$ of the average of the Average Kinetic Coefficients of Friction of all Units of a similar design and capacity, i.e., the Unit must satisfy the following: 


$$
\frac{\left|\mu_{k}-\mu_{k_{A V E}}\right|}{\mu_{k_{A V E}}} \leq 0.15
$$

in which $\mu_{\mathrm{k}}$ is the Average Kinetic Coefficient of Friction of a particular Unit and $\mu_{k_{A V E}}$ is the average of the Average Kinetic Coefficients of Friction of all Units of a similar design and capacity.

For lots of 4 or fewer, due to the low sample size, it is the responsibility of the engineer to decide the acceptance of individual Units based on a review of all available test data.

4.3.8 Report of Results - Results of the tests shall be documented in a clear and concise report. Unless otherwise specified the report should include but is not limited to the following. The name of the laboratory or institution conducting the test, name of the technician and engineer present for the test, name of the technician or engineer responsible for the test, date and time at the start of the test, test configuration (single or dual) and specimen designation.

Pertinent test parameters shall be noted in the report, including vertical load $P_{D}$, displacement $D$, frequency of loading and design temperature $T_{D}$. For each of the 5 complete cycles indicate the maximum and minimum lateral loads, maximum and minimum lateral displacements and Effective Stiffness $\left(K_{H_{i}}\right)$. Note the Average Effective Stiffness $\left(K_{H}\right)$ for the 5 complete cycles and the average of the Average Effective Stiffnesses $\left(K_{H_{\text {vE }}}\right)$ of all Units of a similar design and capacity. Note the Energy Dissipation $\left(E_{H_{i}}\right)$ for each cycle and the Average Energy Dissipation $\left(E_{H}\right)$ over 5 cycles. Note the average of the Average Energy Dissipations $\left(E_{H_{A v E}}\right)$ of all Units of a similar design and capacity. Where applicable report the following: the Static Coefficient of Friction $\left(\mu_{s}\right)$ and the average of the Static Coefficients of Friction $\left(\mu_{s_{A V E}}\right)$ for all Units of a similar design and capacity. For each of the nine half cycles, report the Kinetic Coefficient of Friction $\left(\mu_{k}\right)$, the computed Average Kinetic Coefficient of Friction $\left(\mu_{k}\right)$, and the average of the Average Kinetic Coefficients of Friction $\left(\mu_{k_{A V E}}\right)$ of all Units of a similar design and capacity. The report shall indicate whether the Isolation Unit passed or failed the effective stiffness and energy dissipation test based on the stated performance criteria. For Units that fail the test the report shall explain in sufficient detail the reason for disposition of the Unit. 


\section{SUMMARY}

The 1991 Uniform Building Code and the 1991 AASHTO Guide Specification for Seismic Isolation Design require that all isolation units designed in the United States undergo a series of quality control tests before installation. At the present time, however, standards do not exist for conducting these tests. This report represents the first step in the effort to develop standards for quality control testing of sliding seismic isolation systems.

Guidelines have been presented for conducting production tests and tests on completed isolation units. Six types of production tests have been outlined that are to be conducted on the materials and parts used in the fabrication of an isolation unit. Materials and parts that do not meet or exceed the recommended performance criteria should be rejected. Two completed unit tests have been outlined in the Guidelines: sustained compression, and effective stiffness and energy dissipation. Detailed requirements of the test facility, test procedure, instrumentation, data acquisition, data analysis and reporting of results have been provided. Completed units that do not meet or exceed the stated performance criteria should be set aside for disposition by the engineer of record.

The tests outlined in the Guidelines are a recommended minimum and should be adopted as part the manufacturer's overall quality control program. They have been developed to ensure a minimum level of quality and acceptable performance of seismic isolation systems. 



\section{REFERENCES}

ANSI/ASME B46.1-1985 Surface Texture (Surface Roughness, Waviness and Lay).

ASTM E 4, Standard Practices for Load Verification of Testing Machines.

ASTM E 74, Standard Practice of Calibration of Force-Measuring Instruments for Verifying the Force Indication of Testing Machines.

ASTM E 177, Standard Practice for Use of the Terms Precision and Bias in ASTM Test Methods.

Guide Specifications for Seismic Isolation Design (1991), American Association of State Highway and Transportation Officials, Washington, D.C.

Mostaghel, N. and Khodaverdian, M., 1988, "Seismic Response of Structures Supported on RFBI System," Earthquake Engineering and Structural Dynamics, Vol. 16, pp 839-854.

Shenton, H.W., 1993, "Draft Guidelines for Pre-Qualification and Prototype Testing of Seismic Isolation Systems," NISTIR 5359, National Institute of Standards and Technology, Gaithersburg, Maryland.

Uniform Building Code (1991), International Conference of Building Officials, Whittier, California.

Zayas, V., Low, S. and Mahin, S., 1990 "A Simple Pendulum Technique for Achieving Seismic Isolation," Earthquake Spectra, Vol. 6, May 1990. 



\section{APPENDIX A. SYMBOLS AND NOTATION}

The symbols and notation below apply to the guidelines outlined in this document:

$D \quad=$ Design Displacement;

$D_{c} \quad=$ Creep displacement;

$D_{T M}=$ Total maximum displacement;

$D_{t} \quad=$ Thermal displacement;

$D_{V} \quad=\quad$ Vertical displacement;

$E_{H} \quad=$ Average Energy Dissipation;

$E_{H_{A V E}}=$ average of the Average Energy Dissipations of several Units of a similar design and capacity;

$E_{H_{i}} \quad=$ Energy Dissipation for cycle $i$;

$f_{i}=$ isolation frequency and the inverse of the isolation period $\left(T_{i}\right)$;

$f_{L}, f_{U}=$ lower and upper threshold frequencies, between which the measured response is within a prescribed percentage of the response measured at a frequency of $f_{i}$;

$F \quad=$ lateral load;

$F^{+}, F^{-}=$maximum lateral load $(\max \{F\})$ for a single cycle, minimum lateral load $(\min \{F\})$ for a single cycle;

$F_{A V E}=$ average lateral load over a half cycle;

$F_{B} \quad=$ lateral load due to braking or centrifugal forces;

$F_{s} \quad=$ minimum force required to initiate relative movement across the sliding interface;

$F_{W} \quad=$ wind load;

$K_{H} \quad=\quad$ Average Effective Stiffness;

$K_{H_{A V E}}=$ average of the Average Effective Stiffnesses of several Units of a similar design and capacity;

$K_{H_{i}} \quad=\quad$ Effective Stiffness for cycle $i$;

$K_{V}=$ Average Effective Vertical Stiffness at the Design Vertical Load;

$K_{W} \quad=$ Effective Stiffness at the Design Wind Load;

$N_{D} \quad=$ degradation cycle limit;

$N_{t} \quad=$ thermal cycle limit;

$P \quad=$ vertical load; 


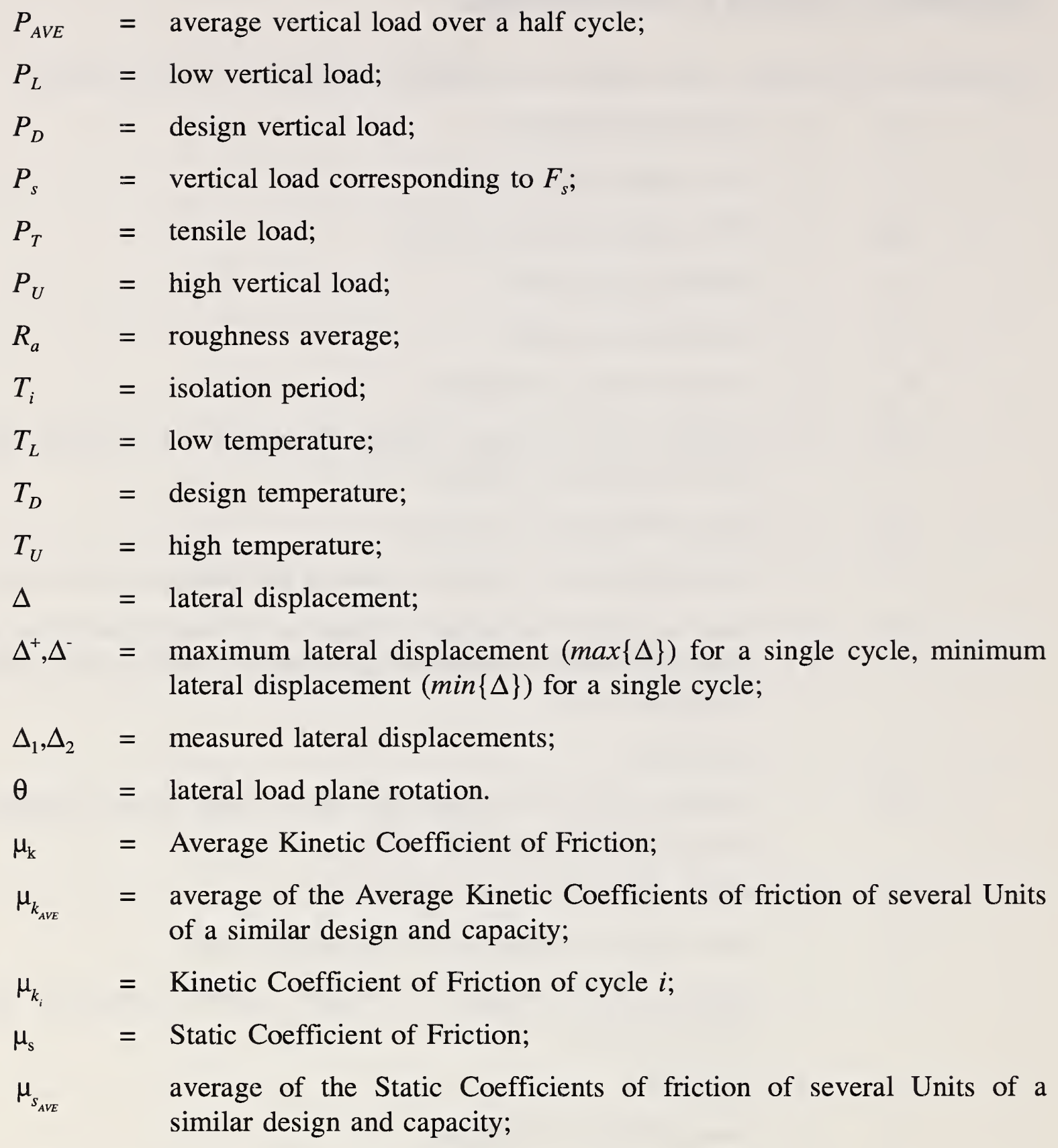




\section{APPENDIX B. GLOSSARY OF TERMS}

The definitions below apply to the guidelines outlined in this document:

Average Effective

Stiffness

Average Energy

Dissipation

Design Displacement

Effective Stiffness

Energy Dissipation

Frequency of Load

Hysteresis Loop

Isolation Component

Isolation System

Isolation Unit

Isolation Interface
The average of the Effective Stiffnesses over a number of cycles for a specified set of test conditions.

The average of the Energy Dissipation over a prescribed number of cycles for a specified set of test conditions.

The minimum lateral seismic displacement at the center of rigidity required for design of Isolation System, exclusive of additional displacement due to torsion.

Lateral force in the Isolation Unit divided by the lateral displacement.

The area enclosed by a single hysteresis loop.

The number of full cycles of loading completed per unit time, usually expressed as cycles/second.

A curve generated by plotting force versus displacement, which under cyclic loading generally forms a loop.

A flexible structural element of the Isolation System which permits large lateral deformations under seismic excitation. An Isolation Component provides primarily a restoring force or damping attribute in a single structural element. An Isolation Component may also be used as a structural member for non-seismic loads. An Isolation Component in and of itself cannot fulfill the restoring force and energy dissipation properties required of the System.

The collection of structural elements that includes all individual Isolation Units, Components, other structural members and connections that transfer force between the substructure and superstructure and form the isolation interface. The Isolation System also includes any other lateral restraint system that is utilized to resist non-seismic loads, or serves as an ultimate restraint device.

A flexible structural element of the Isolation System which permits large lateral deformations under seismic excitation. An Isolation Unit provides all restoring force and damping attributes in a single integrated structural element. An Isolation Unit may also be used as a structural member for non-seismic loads.

The boundary between the upper portion of the structure (superstructure) which is isolated, and the lower portion of the structure (substructure) which is not isolated. 
Kinetic Coefficient of Defined as the lateral shear force acting on the sliding interface friction divided by the normal force during relative movement across the interface.

Precision

A "generic concept related to the closeness of agreement between test results obtained under prescribed like conditions from the measurement process being evaluated" (ASTM E 177-90a).

Rate of Load

The velocity of the actuator or load fixture expressed as distance per unit time.

Static Coefficient of Defined as the lateral shear force required to initiate relative movement Friction across the sliding interface, divided by the normal force.

Total Design

Displacement

The minimum lateral seismic displacement at the center of rigidity required for design of Isolation System, including the additional displacement due to torsion.

Uncertainty

A statistical estimate of the error limits of a quantity obtained from a calibration equation (ASTM E 74-91). 

. 